\title{
Stress redistribution in multi-stage hydraulic fracturing of horizontal wells in shales
}

\author{
Yi-Jin Zeng ${ }^{1} \cdot$ Xu Zhang ${ }^{1} \cdot$ Bao-Ping Zhang ${ }^{1}$
}

Received: 11 May 2015/Published online: 18 September 2015

(c) The Author(s) 2015. This article is published with open access at Springerlink.com

\begin{abstract}
Multi-stage hydraulic fracturing of horizontal wells is the main stimulation method in recovering gas from tight shale gas reservoirs, and stage spacing determination is one of the key issues in fracturing design. The initiation and propagation of hydraulic fractures will cause stress redistribution and may activate natural fractures in the reservoir. Due to the limitation of the analytical method in calculation of induced stresses, we propose a numerical method, which incorporates the interaction of hydraulic fractures and the wellbore, and analyzes the stress distribution in the reservoir under different stage spacing. Simulation results indicate the following: (1) The induced stress was overestimated from the analytical method because it did not take into account the interaction between hydraulic fractures and the horizontal wellbore. (2) The hydraulic fracture had a considerable effect on the redistribution of stresses in the direction of the horizontal wellbore in the reservoir. The stress in the direction perpendicular to the horizontal wellbore after hydraulic fracturing had a minor change compared with the original in situ stress. (3) Stress interferences among fractures were greatly connected with the stage spacing and the distance from the wellbore. When the fracture length was $200 \mathrm{~m}$, and the stage spacing was $50 \mathrm{~m}$, the stress redistribution due to stage fracturing may divert the original stress pattern, which might activate natural fractures so as to generate a complex fracture network.
\end{abstract}

Yi-Jin Zeng

zengyj.sripe@sinopec.com

1 Sinopec Research Institute of Petroleum Engineering, Beijing 100101, China

Edited by Yan-Hua Sun
Keywords Shale gas $\cdot$ Horizontal well $\cdot$ Multi-stage fracturing $\cdot$ Complex fracture $\cdot$ Stage spacing $\cdot$ Induced stress

\section{Introduction}

Multi-stage fracturing in horizontal wells is an important and effective completion method for compact, low permeability reservoirs (Cai et al. 2009; Yao et al. 2013; Koløy et al. 2014; Li et al. 2014; Sorek et al. 2014; Zhang and $\mathrm{Li}$ 2014). The essence of hydraulic fracturing is to inject high-pressure fluids into a reservoir to create induced fractures around the wellbore. As a reliable and economic formation stimulation technology, it has been successfully used in shale gas reservoirs. Due to low matrix porosity and low permeability of shale gas reservoirs, to make long well lengths for effective drainage areas in traditional designs, it is not practical for tight shales (Zhou et al. 2010; Zeng et al. 2010; Wu et al. 2011, 2012; Wang et al. 2014a). In order to create complex fractures in shale reservoirs through multi-stage hydraulic fracturing in horizontal wells, analysis of stage spacing and stress interference among fractures needs to be done.

Stress distribution around a horizontal wellbore is very complex, affected by filtration of fracturing fluids, pore pressure, etc. (Fischer et al. 1994; Economides 2006; Civan 2010; Fang and Khaksar 2011; Zhang et al. 2012; Ziarani and Aguilera 2012; Hou et al. 2013; Pan et al. 2014; Chen et al. 2015). Meanwhile, previous stages of hydraulic fracturing would affect later stages of fracturing (Xu 2009; Wei et al. 2011; Chuprakov et al. 2011; Wang et al. 2014b).

Some researchers investigated optimization of hydraulic fracturing based on a one-factor analysis of fracture parameters and evaluated effects of fracture parameters on 
productivity of horizontal wells (Zhu et al. 2013). A new grid refinement was used to optimize fracturing parameters. Effects of the horizontal-section length, number of fractures, fracture length, and conductivity on the productivity of horizontal wells were also studied (Chen et al. 2013). An optimization method for perforation spacing was established, it included a mathematical model of the induced stress field on the basis of a homogeneous and isotropic 2D plane strain model and the shift between the maximum and minimum horizontal principal stress (Yin et al. 2012). Qu et al. put forward a design method for optimizing horizontal well fracturing parameters (Qu et al. 2012). Shang et al. established a wellbore stress distribution model and a fracture pressure calculation model (Shang et al. 2009).

In the above-mentioned research, an analytical method based on classic fracture mechanics was used to analyze characteristics of the fracture-induced stress field in hydraulic fracturing, but this model did not consider interaction between fractures and the horizontal wellbore, so did not explicitly give characteristics of different stages of spacing and stress interference among fractures.

On the basis of analyzing limitations of the classical analytical method, a comparative analysis of the numerical method is carried out. With the numerical model, we analyze in situ stress change and interference among fractures.

\section{Fracture geometry and net pressure for multi- stage fractured horizontal wells}

\subsection{Fracture geometry}

During hydraulic fracturing, a fracturing fluid is injected continuously into the formation, and fractures will propagate dynamically. However, it is difficult to predetermine the fracture geometry using the pressure distribution function. While using the criterion of $K_{\mathrm{I}}=K_{\mathrm{Ic}}$ at each moment, the hydraulic mechanical coupling problem can be solved.

From the theory of fracture mechanics and the Castigliano theorem, the width of a fracture under plain strain conditions can be calculated from the following equation:

$w(y)=\frac{4}{\pi E} \int_{y}^{a}\left[\int_{-\xi}^{\xi} \Delta p(y) \sqrt{\frac{\xi+y}{\xi-y}} \mathrm{~d} y\right] \frac{1}{\sqrt{\xi^{2}-y^{2}}} \mathrm{~d} \xi$,

where $\Delta p(y)=p(y)-\sigma_{\mathrm{h}}$ is the net pressure in the fracture; $p(y)$ is the fluid pressure; $\sigma_{\mathrm{h}}$ is the minimum horizontal in situ stress perpendicular to the fracture plane; $E$ is the elastic modulus of the rock; $a$ is the fracture half length; $\xi$ is the temporary fracture half length during integration, as shown in Fig. 1.

When the net pressure is distributed smoothly and continuously along the fracture, it can be defined by a

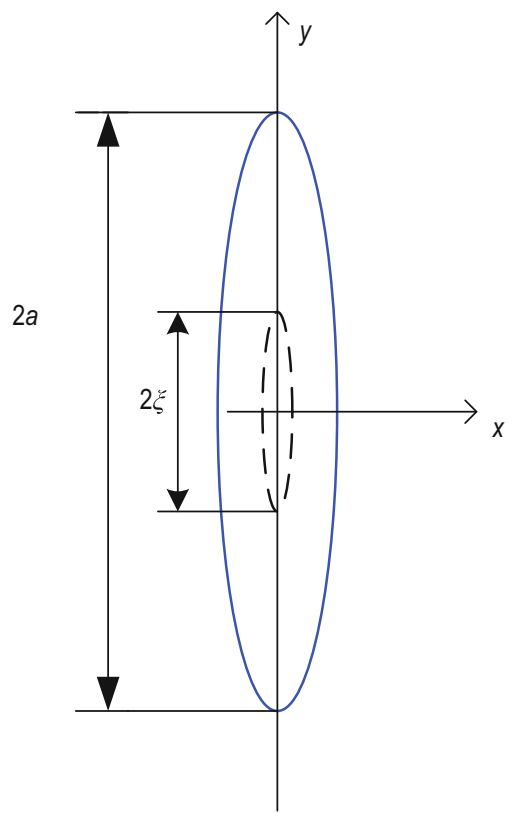

Fig. 1 Geometry of a hydraulic fracture

continuous function $p(y)=p_{\mathrm{w}} f(y)$. The stress intensity factor $K_{\mathrm{I}}$ at the fracture tip can be expressed as

$$
\begin{aligned}
K_{\mathrm{I}} & =\frac{1}{\sqrt{\pi a}} \int_{-a}^{a}\left[p(y)-\sigma_{\mathrm{h}}\right] \sqrt{\frac{a+y}{a-y}} \mathrm{~d} y \\
& =\frac{1}{\sqrt{\pi a}} \int_{-a}^{a}\left[p_{\mathrm{w}} f(y)-\sigma_{\mathrm{h}}\right] \sqrt{\frac{a+y}{a-y}} \mathrm{~d} y
\end{aligned}
$$

where $p_{\mathrm{w}}$ is the wellbore pressure; $f(x)$ is the eigen function of the pressure distribution.

According to the mean value theorem of integral, Eq. (2) becomes

$K_{\mathrm{I}}=A p_{\mathrm{w}} \sqrt{a}-\sigma_{\mathrm{h}} \sqrt{\pi a}$,

where $A=\frac{2}{\pi} f(b) \sqrt{\frac{a+b}{a-b}}(-a<b<a)$ is a constant, and $A=\frac{\sigma_{\mathrm{h}} \sqrt{\pi a}+K_{\mathrm{I} c}}{p_{\mathrm{w}} \sqrt{a}}$ considering the fracture propagation criterion $K_{\mathrm{I}}=K_{\mathrm{Ic}}$.

Substituting Eq. (3) into (1) and integrating it give

$w(y)=\frac{4}{E} K_{\mathrm{Ic}} \sqrt{\frac{a^{2}-y^{2}}{\pi a}}$,

where $K_{\mathrm{Ic}}$ is the fracture toughness of the target zone. From Eq. (4), it can be seen that the fracture cross section is a slim ellipse determined by the fracture half length $a, E, K_{\mathrm{Ic}}$, and independent of the pressure distribution in it.

\subsection{Net pressure}

We assume that the fracturing fluid is incompressible, and the formation is impermeable, then the fracture volume is equal to the volume of the fluid injected into the formation. 
$Q=V(a)=\frac{2 K_{\mathrm{Ic}} h a \sqrt{\pi a}}{E}$,

$Q=q t$

where $q$ is the injection rate; $t$ is the injection time.

The fracture parameters can be obtained as

$a=\left(\frac{q E t}{2 \sqrt{\pi} h K_{\mathrm{Ic}}}\right)^{2 / 3}$,

$w(0)=\frac{4 K_{\mathrm{Ic}}}{E \sqrt{\pi}}\left(\frac{q E t}{2 \sqrt{\pi} h K_{\mathrm{Ic}}}\right)^{1 / 3}$.

Using fluid mechanics theory, the distribution of the net pressure can be approximated by a linear equation:

$p(y)=p_{\mathrm{w}}\left(1-0.42 \frac{y}{a}\right)$.

Substituting Eq. (9) into (2) gives the wellbore pressure $p_{\mathrm{w}}$ :

$p_{\mathrm{w}}=\frac{0.77 K_{\mathrm{Ic}}}{\sqrt{a}}+1.365 \sigma_{\mathrm{h}}$.

The fluid pressure distribution $p(y)$ and the tip pressure $p_{\mathrm{a}}$ are

$p(y)=\left(\frac{0.77 K_{\mathrm{Ic}}}{\sqrt{a}}+1.365 \sigma_{\mathrm{h}}\right)\left(1-0.42 \frac{y}{a}\right)$,

$p_{\mathrm{a}}=\frac{0.45 K_{\mathrm{Ic}}}{\sqrt{a}}+0.79 \sigma_{\mathrm{h}}=0.58 p_{\mathrm{w}}$.

Equations (11) and (12) indicate that the tip pressure $p_{\mathrm{a}}$ is not 0 , and the wellbore pressure $p_{\mathrm{w}}$ should be always greater than the minimum horizontal stress $\sigma_{\mathrm{h}}$ to maintain the fracture propagation considering the pressure drop.

\section{In situ stress model for multi-stage fractured horizontal wells}

Due to shale formations of low permeability, multi-stage hydraulic fracturing of horizontal wells is used to interact with natural fractures and weak bedding planes, to create as many crossing fractures as possible to maximize the stimulated reservoir volume. During stage fracturing, the main hydraulic fractures are created one after another. When a main fracture is formed, there will exist an induced stress field around the fracture, which influences the in situ stress field around it. The superposition of the induced stress field and the in situ stress field will affect the initiation and propagation of subsequent fractures. At present, classical fracture mechanics theory is used to calculate the stress field after fracturing.

\subsection{Limitation of the classical analytical method}

According to the theory of fracture mechanics, a two-dimensional model was established, based on the assumption of homogeneity, isotropy, and plane strain conditions, to calculate the induced stress field, as shown in Fig. 2.

We assume that the fracture is vertical, its longitudinal section is elliptical, and the height is $H$. $z$-axis is along the fracture height direction. $x$-axis is along the horizontal wellbore, and $y$-axis is along the direction of the maximum horizontal stress. It is assumed that the tensile stress is positive and the compressive stress is negative. The induced stresses at an arbitrary point $(x, y, z)$ are as follows (Yin et al. 2012):

$$
\left\{\begin{aligned}
\sigma_{x}= & -p \frac{r}{c}\left(\frac{c^{2}}{r_{1} r_{2}}\right)^{\frac{3}{2}} \sin \beta \sin \left[\frac{3}{2}\left(\beta_{1}+\beta_{2}\right)\right] \\
& +p\left[\frac{r}{\left(r_{1} r_{2}\right)^{\frac{1}{2}}} \cos \left(\beta-\frac{1}{2} \beta_{1}-\frac{1}{2} \beta_{2}\right)-1\right] \\
\sigma_{z}= & p \frac{r}{c}\left(\frac{c^{2}}{r_{1} r_{2}}\right)^{\frac{3}{2}} \sin \beta \sin \left[\frac{3}{2}\left(\beta_{1}+\beta_{2}\right)\right] \\
& +p\left[\frac{r}{\left(r_{1} r_{2}\right)^{\frac{1}{2}}} \cos \left(\beta-\frac{1}{2} \beta_{1}-\frac{1}{2} \beta_{2}\right)-1\right] \\
\sigma_{y}= & v\left(\sigma_{x}+\sigma_{z}\right) \\
\tau_{x z}= & -p \frac{r}{c}\left(\frac{c^{2}}{r_{1} r_{2}}\right)^{\frac{3}{2}} \sin \beta \sin \left[\frac{3}{2}\left(\beta_{1}+\beta_{2}\right)\right]
\end{aligned}\right.
$$

with

$c=H / 2$,

where $\sigma_{x}, \sigma_{y}$, and $\sigma_{z}$ are the three normal stress components induced by a fracture, $\mathrm{MPa} ; \tau_{x z}$ is the shear component, $\mathrm{MPa} ; p$ is the fluid pressure, $\mathrm{MPa} ; v$ is the Poisson ratio.

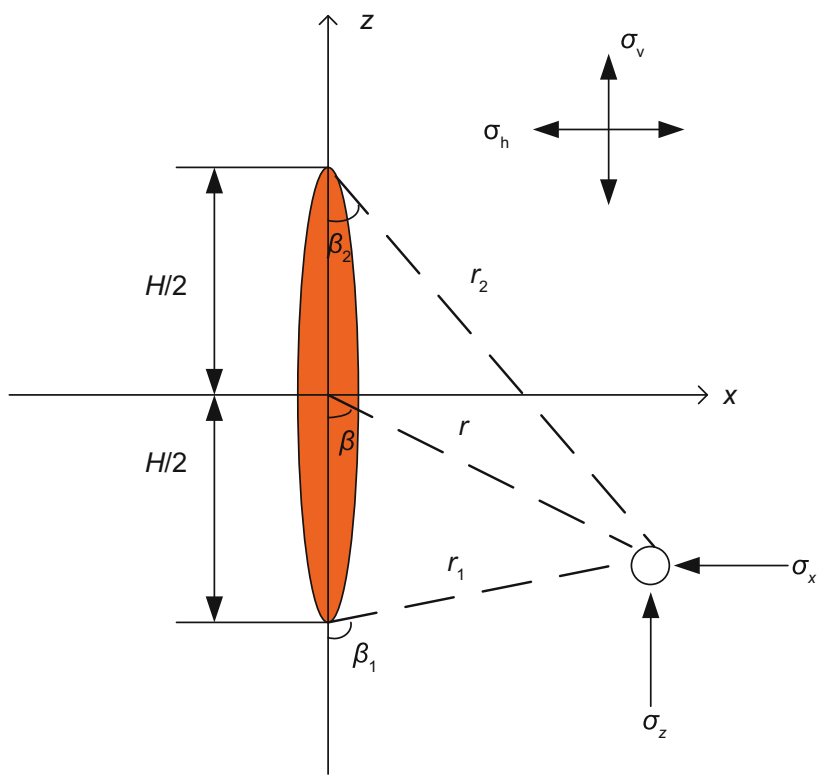

Fig. 2 Stress field induced by a hydraulic fracture 
The relationships between these parameters are as follows:

$$
\left\{\begin{array}{l}
r=\sqrt{x^{2}+z^{2}} \\
r_{1}=\sqrt{x^{2}+(c-z)^{2}} \\
r_{2}=\sqrt{x^{2}+(c+z)^{2}} \\
\beta=\arctan \left(-\frac{x}{c}\right) \\
\beta_{1}=\arctan \left(\frac{x}{c-z}\right) \\
\beta_{2}=\arctan \left(-\frac{x}{c+z}\right)
\end{array}\right.
$$

In situ stresses are composed of $\sigma_{x}, \sigma_{y}$, and $\sigma_{z}$. The stress field around a later fracture may be a summation of induced stresses of the former fractures and the in situ stresses. According to the principle of superposition, the stress field around the $n$th fracture was studied by Zhang and Chen (2010a, b, c):

$$
\left\{\begin{array}{l}
\sigma_{\mathrm{H}(n)}^{\prime}=\sigma_{\mathrm{H}}+v\left(\sum_{i=1}^{n-1} \sigma_{x(i n)}+\sum_{i=1}^{n-1} \sigma_{z(i n)}\right) \\
\sigma_{\mathrm{h}(n)}^{\prime}=\sigma_{\mathrm{h}}+\sum_{i=1}^{n-1} \sigma_{x(i n)}, \\
\sigma_{\mathrm{v}(n)}^{\prime}=\sigma_{\mathrm{v}}+\sum_{i=1}^{n-1} \sigma_{z(i n)}
\end{array}\right.
$$

where $\sigma_{\mathrm{H}(n)}^{\prime}, \sigma_{\mathrm{h}(n)}^{\prime}$, and $\sigma_{\mathrm{v}(n)}^{\prime}$ are the three principal stresses around the $n$th fracture, MPa; $\sigma_{x(i n)}, \sigma_{y(i n)}$, and $\sigma_{z(i n)}$ are the induced stress components around the $n$th fracture caused by the $i$ th fracture, MPa.

When a new fracture is formed, it will produce an induced stress field which can be calculated by Eq. (13). Superimposing the newly induced stress field on the old one gives the final stress field (Eq. 15). This method just considers the effect of hydraulic fractures on the stress field but ignores the influence of the horizontal well. So it is limited and cannot provide the exact value of the stress field.

Because the stress field around the horizontal wellbore changes dramatically, the effect of the horizontal wellbore on the stress field distribution should be considered. Numerical calculation can achieve the above purpose.

\subsection{Numerical method for in situ stress field in horizontal wells}

The initial stress field around the wellbore will be disturbed and redistributed in the shale reservoir during drilling and completion operations. When the first hydraulic fracture is formed, the in situ stress field around the hydraulic fracture and the wellbore will be redistributed. So interaction between fractures and the horizontal wellbore should be considered when calculating the variation of stress in horizontal well fracturing.

Considering interaction between fractures and the horizontal wellbore, analysis of the in situ stress field can be simplified as a plane strain problem. In this analysis, the stress induced by the change of reservoir temperature is ignored, and the fluid flowing in fractures is incompressible.

Figure 3 shows a model of stress fields considering interaction between fractures and the horizontal wellbore.

In order to reduce calculation time, we considered symmetrical geometry, in which we would calculate the stress field in the finite element model.

\section{Comparison of classical analytical and numerical methods}

The stress difference around a fracture before and after fracturing can be expressed as

$\left\{\begin{array}{l}\sigma_{\mathrm{a} x}=\sigma_{\mathrm{h}}^{\prime}-\sigma_{\mathrm{h}} \\ \sigma_{\mathrm{a} y}=\sigma_{\mathrm{H}}^{\prime}-\sigma_{\mathrm{H}} \\ \sigma_{\mathrm{a} z}=\mu\left(\sigma_{\mathrm{a} x}+\sigma_{\mathrm{a} y}\right)\end{array}\right.$,

where $\sigma_{\mathrm{h}}^{\prime}$ and $\sigma_{\mathrm{H}}^{\prime}$ are the minimum and maximum horizontal stresses around the fracture after fracturing, respectively.

The main parameters used in numerical simulation are shown Tables 1 and 2 .

The induced stress in the first stage of fracturing is closely related to the net pressure and the fracture length. The induced stress is a function of the distance away from

Table 1 Mechanical parameters of the shale reservoir

\begin{tabular}{lllll}
\hline$E_{1}, \mathrm{GPa}$ & $E_{2}, \mathrm{GPa}$ & $v_{1}$ & $v_{2}$ & $G_{12}, \mathrm{GPa}$ \\
\hline 24.910 & 14.093 & 0.324 & 0.367 & 7.814 \\
\hline
\end{tabular}

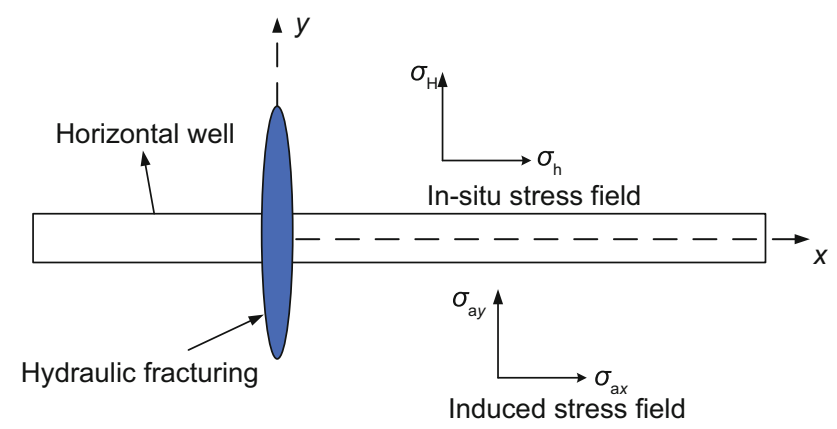

Fig. 3 Stress fields considering interaction between fractures and the horizontal wellbore 
Table 2 Input parameters

\begin{tabular}{|c|c|c|c|c|c|c|c|c|c|}
\hline $\begin{array}{l}\text { Well } \\
\text { depth, } \\
\text { m }\end{array}$ & $\begin{array}{l}\text { Wellbore } \\
\text { length, m }\end{array}$ & $\begin{array}{l}\text { Minimum } \\
\text { horizontal stress, } \\
\mathrm{MPa}\end{array}$ & $\begin{array}{l}\text { Maximum } \\
\text { horizontal stress, } \\
\text { MPa }\end{array}$ & $\begin{array}{l}\text { Reservoir } \\
\text { pressure, } \\
\mathrm{MPa}\end{array}$ & $\begin{array}{l}\text { Net } \\
\text { pressure, } \\
\text { MPa }\end{array}$ & $\begin{array}{l}\text { The model } \\
\text { length, } \mathrm{m}\end{array}$ & $\begin{array}{l}\text { The model } \\
\text { width, } \mathrm{m}\end{array}$ & $\begin{array}{l}\text { Fracture } \\
\text { length, m }\end{array}$ & $\begin{array}{l}\text { Facture } \\
\text { width, } \\
\mathrm{mm}\end{array}$ \\
\hline 2410 & 1000 & 50 & 65 & 33 & 10 & 2000 & 2000 & 200 & 2 \\
\hline
\end{tabular}

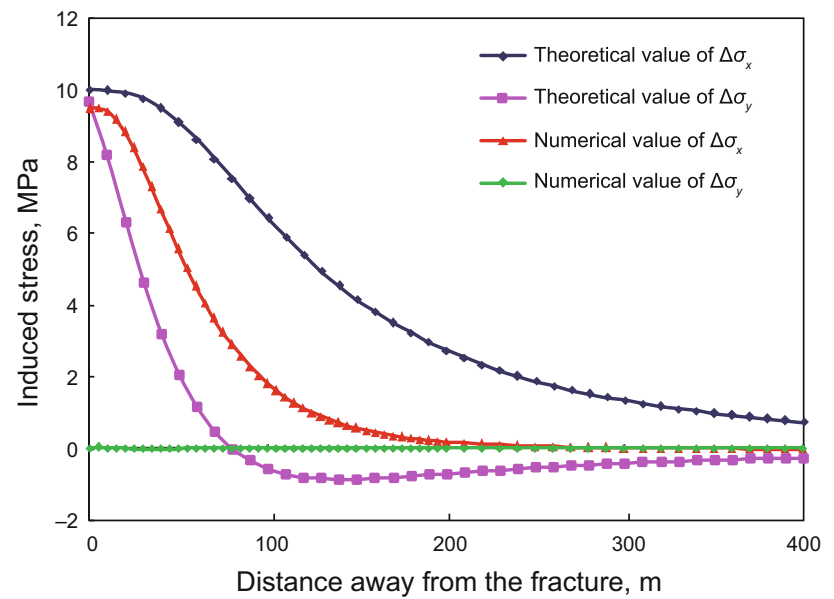

Fig. 4 Relationship between the induced stress field and the distance away from the fracture

the first fracture. Figure 4 shows the induced stress from the classical analytical and numerical methods.

Ignoring the interaction between the fracture and the wellbore (in the analytical model), the stress induced by the first fracture is relatively high in the wellbore direction. The theoretical method overestimates the induced stress in the horizontal wellbore direction. The induced stress in the $y$-axis direction decreases rapidly. However, the induced stress around the wellbore is affected by the wellbore. Generally, the induced stress in the minimum horizontal stress direction is greater than that in the maximum horizontal stress direction, so the difference between the maximum and minimum stresses will reduce. The fracture may turn when the stress difference reaches a certain value. This would provide favorable conditions for creating complex fractures and communicating with natural fractures in the propagation of hydraulically induced fractures.

Figure 5 shows that the stress difference calculated from the classical analytical method is relatively low in the region close to the fracture, when not considering the interaction between fractures and the wellbore. On the other hand, the stress difference calculated from the analytical method is relatively high in the region far away from the fracture.

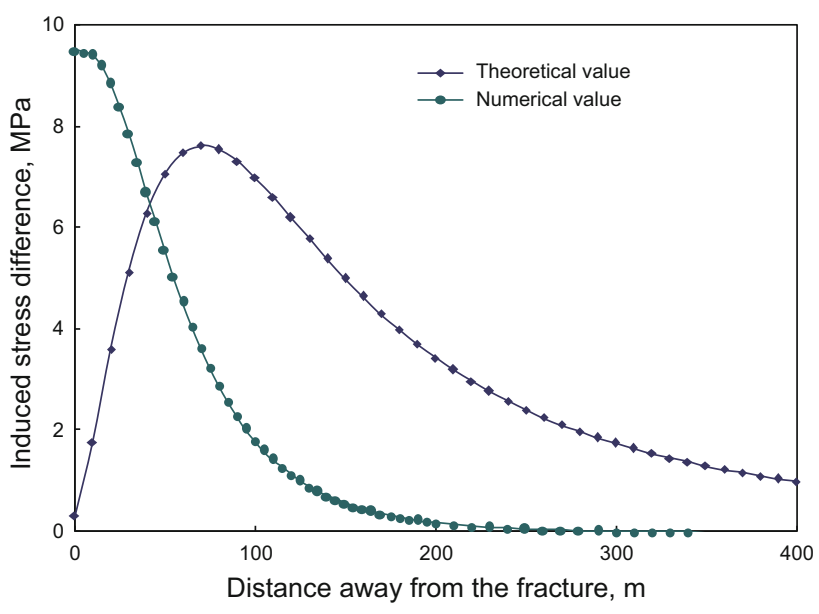

Fig. 5 Relationship between the induced stress difference and the distance away from the fracture

\section{Distribution of the induced stress with different spacing among fracturing stages}

As shown in Figs. 4 and 5, the induced stress is related to the distance away from the fracture. With an increase in the fracture spacing in two stages of fracturing, the stress difference decreases gradually.

Therefore, in order to create a fracture network to improve well productivity in shale reservoirs, we should try to reduce the fracture spacing between the two stages. When the fracture spacing is too small, not only would it waste fracturing materials and resources, but also it cannot achieve the expected economic benefits.

In this paper, the stress field is studied with the numerical method at different fracture spacing.

\subsection{Fracture reorientation criterion}

When the net pressure in the fracture is greater than the stress difference between the minimum and maximum horizontal stresses plus reservoir rock tensile strength, a branch of fractures may be initiated (Sam et al. 2011; Zhao et al. 2012; Jiang 2013).

$\sigma_{\mathrm{H}}+\sigma_{y} \leq \sigma_{\mathrm{h}}+\sigma_{x}$ 
Equation (7) can be changed to

$\sigma_{x}-\sigma_{y} \geq \sigma_{\mathrm{H}}-\sigma_{\mathrm{h}}$

When Eq. (18) is satisfied, a branch fracture may deviate from the original extension path and extend along the horizontal wellbore as shown in Fig. 6.

Formation mechanisms of a complex fracture network are as follows:

(1) To form a plurality of main fractures in the formation, the stress induced by fracturing might change the initial stress pattern.

(2) Proper fracture spacing to create reasonably large induced stress so as to make the fracture reorient and to make connections with natural fractures.

\subsection{Stress change under different fracture spacing}

Figure 7 shows the change of stress with varied fracture spacing of 50,100 , and $150 \mathrm{~m}$. This indicates that stress concentration around the fracture will be strengthen as fracture spacing reduces. When the fracture spacing is $50 \mathrm{~m}$, the maximum stress along the wellbore direction is in the middle of the two fractures. When it increases to $100 \mathrm{~m}$, the maximum stress will be in the region near the fractures, and the minimum is in the middle of fractures. The shape of distribution of stress along the wellbore direction is similar to a funnel. When it changes to $150 \mathrm{~m}$, the maximum stress is in the region near the fractures. So, the stress along the wellbore direction increases remarkably, and the interference of two fractures is strong when the fracture was $50 \mathrm{~m}$ apart. When the fractures were 100 and $150 \mathrm{~m}$ apart, the stress will be reduced and the degree of interference is also weakened.

Figure 8 shows a change of stress in the direction perpendicular to the wellbore direction at different fracture spacing of 50,100 , to $150 \mathrm{~m}$. This indicates that the existence of the wellbore plays a dominate role in the change of stress.

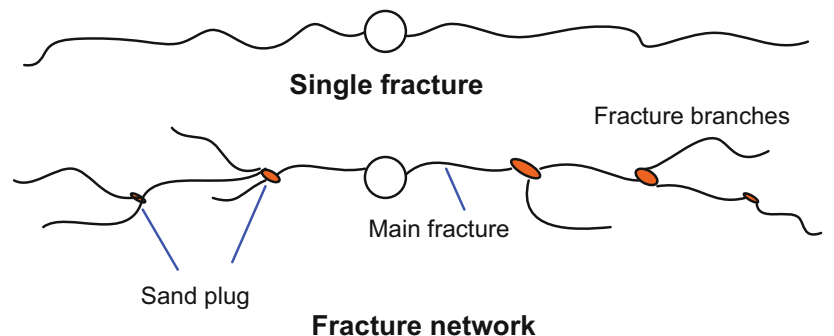

Fig. 6 Comparison of a single fracture and a complex fracture network

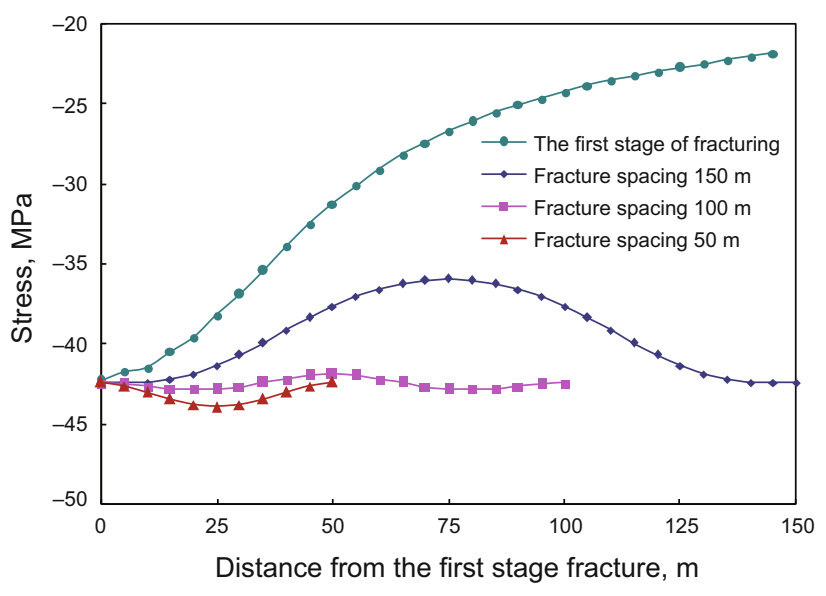

Fig. 7 Change of stress with fracture spacing in the wellbore direction

Figure 9 shows a change of difference between the maximum and minimum stresses in the wellbore direction at different fracture spacing. This indicates that the difference will be large when the fracture spacing is small. So it may change the horizontal stress pattern between horizontal stresses, which would be helpful in the formation of a complicated fracture network. However, the difference of horizontal stresses parallel and perpendicular to the wellbore would decrease as the fracture spacing increases.

Figure 10 shows a change of stress at the fracture tips parallel to the wellbore as the fracture spacing varies from 50,100 , to $150 \mathrm{~m}$. This indicates that the smaller the fracture spacing, the higher the stress at the fracture tip and the stronger the interference between stresses. This would increase the likelihood of fracture reorientation and the formation of a complex fracture network. While with an increase in the fracture spacing, a high stress appears only near fractures and they have strong interference. In the

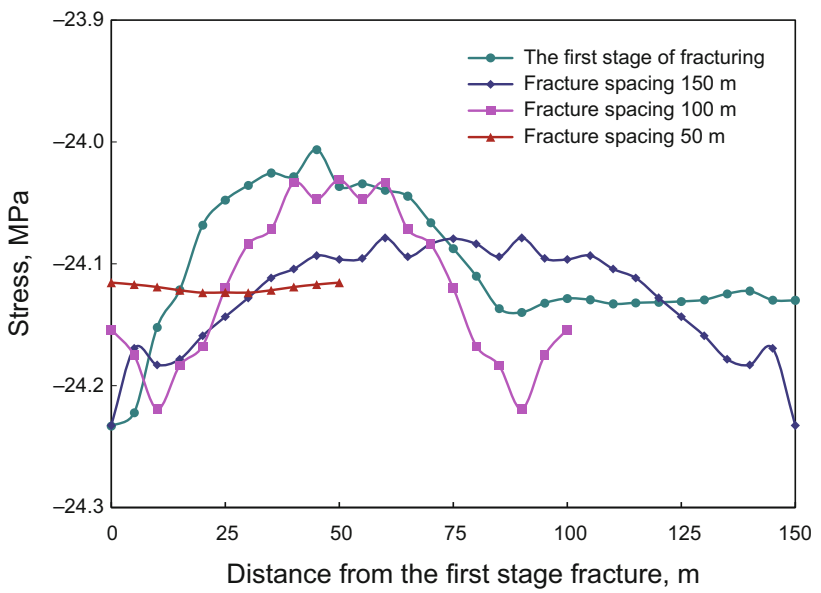

Fig. 8 Change of stress perpendicular to the wellbore direction at different fracture spacing 


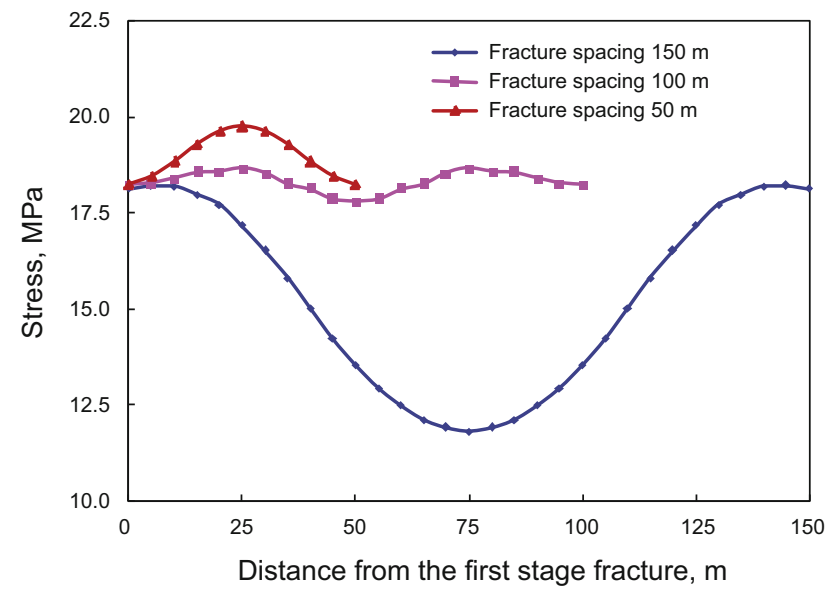

Fig. 9 Change of difference between the maximum and minimum horizontal stresses in the wellbore direction at different fracture spacing

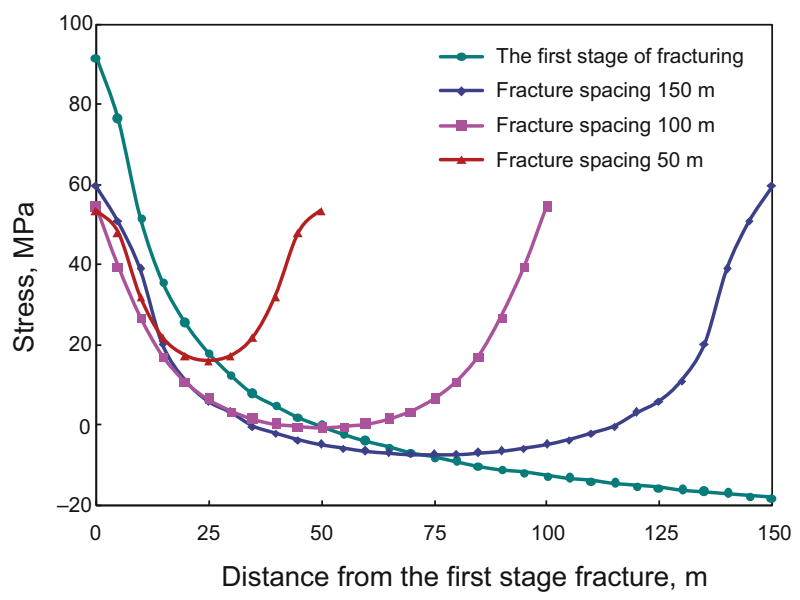

Fig. 10 Stress near fracture tips in the wellbore direction at different fracture spacing

central area between fractures, the stress interference is much less, so the creation of a complex fracture network is unlikely.

Figure 11 shows the change of stress at fracture tips in the direction perpendicular to the wellbore. This demonstrates that the influenced region is quite limited as the fracture spacing increases. When the fracture spacing extends the influenced region, the stress would be mainly influenced by the wellbore.

So the stress interference between fractures is closely related to the fracture spacing and the distance from the wellbore in stage fracturing of the horizontal well. The change of stress in the wellbore direction is mainly affected by the fracture spacing while the distance from the wellbore dominates the change of stress in the direction perpendicular to the wellbore. When the fracture spacing is $50 \mathrm{~m}$, the horizontal stress pattern may be changed; the

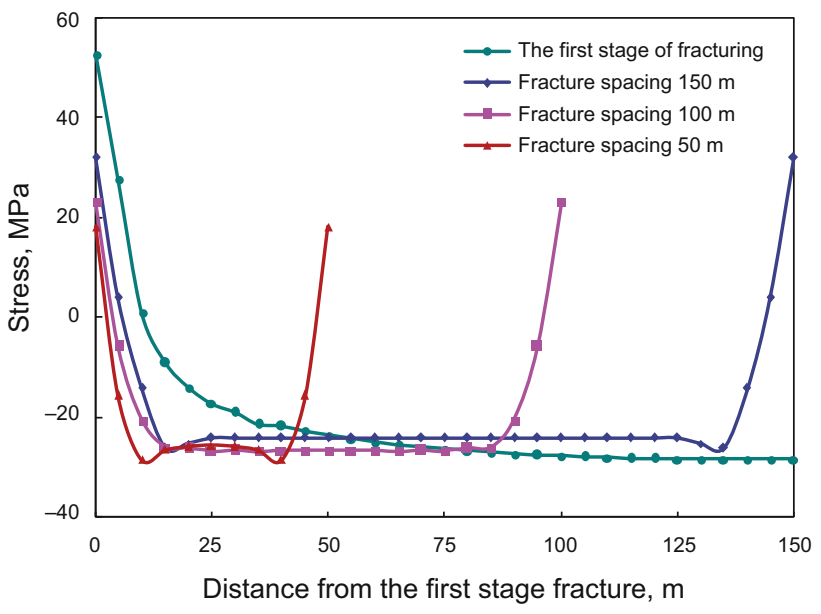

Fig. 11 Stress near fracture tips in the direction perpendicular to the wellbore at different fracture spacing

original maximum stress turns to the minimum and vice versa due to high induced stress, and it may connect natural fractures more effectively so as to create a complex fracture system more easily.

\section{Conclusions}

(1) A comparison was made between the traditional classic analytical and numerical methods in analysis of stress in multi-stage fracturing of horizontal wells. The analytical method did not take into account interaction among fractures and the horizontal wellbore when analyzing the induced stress, so a high stress was predicted in the minimum horizontal stress direction and the influence of the induced stress from fracturing was overestimated. In addition, the induced stress in the maximum horizontal stress direction was influenced by near wellbore effects. So the analytical method has its limitations, and the numerical method can provide more reasonable results.

(2) The induced stress along wellbore direction from fracturing may significantly influence the stress distribution around the horizontal wellbore. The influence will gradually reduce to its original stress in the far field. Stress redistribution in the direction perpendicular to the wellbore is mainly influenced by near wellbore effects.

(3) The stress interference is related to fractures and near wellbore effects in multi-stage fracturing of horizontal wells. The stress along the wellbore is mainly influenced by the fracture spacing. For a fracture with $200 \mathrm{~m}$ length, fracture reorientation may occur due to high induced stress so as to create complex fractures when the fracture spacing is around $50 \mathrm{~m}$. 
Acknowledgments This research was supported by the Natural Science Foundation of China (Grant No. 51490653, Basic Theoretical Research of Shale Oil and Gas Effective Development).

Open Access This article is distributed under the terms of the Creative Commons Attribution 4.0 International License (http://crea tivecommons.org/licenses/by/4.0/), which permits unrestricted use, distribution, and reproduction in any medium, provided you give appropriate credit to the original author(s) and the source, provide a link to the Creative Commons license, and indicate if changes were made.

\section{References}

Cai WB, Li ZM, Zhang XL, et al. Horizontal well fracturing technology for reservoirs with low permeability. Pet Explor Dev. 2009;36(1):80-5.

Chen FJ, Tang Y, Liu SD, et al. Study of the optimization of staged fracturing of a horizontal well in a tight gas reservoir with low permeability. Spec Oil Gas Reserv. 2013;19(6):85-7 (in Chinese)

Chen JN, Li TT, Zhang Y. Application of the unstructured grids in the numerical simulation of fractured horizontal wells in ultra-low permeability gas reservoirs. $J$ Nat Gas Sci Eng. 2015;22(1):580-90. doi:10.1016/j.jngse.2015.01.003.

Chuprakov DA, Akulich AV, Siebrits E, et al. Hydraulic-fracture propagation in a naturally fractured reservoir. SPE Prod Oper. 2011;26(1):88-97.

Civan F. Effective correlation of apparent gas permeability in tight porous media. Transp Porous Media. 2010;82(2):375-84.

Economides MJ. Reservoir stimulation. Beijing: Petroleum Industry Press; 2006. p. 90-125.

Fang Z, Khaksar A. Complexity of minifrac tests and implications for in situ horizontal stresses in coalbed methane reservoirs. In: International petroleum technology conference, 7-9 February, Bangkok, Thailand, 2011.

Fischer MP, Gross MR, Engelder T, et al. Finite-element analysis of the stress distribution around a pressurized crack in a layered elastic medium: implications for the spacing of fluid-driven joints in bedded sedimentary rock. Tectonophysics. 1994;247(1):49-64.

Hou B, Chen M, Wang Z, et al. Hydraulic fracture initiation theory for a horizontal well in a coal seam. Pet Sci. 2013;10(2):219-25. doi:10.1007/s12182-013-0270-9.

Jiang TX. The fracture complexity index of horizontal wells in shale oil and gas reservoirs. Pet Drill Tech. 2013;41(2):7-12 (in Chinese).

Koløy TR, Brække K, Sørheim T, et al. The evolution, optimization $\&$ experience of multistage frac completions in a North Sea environment. In: SPE annual technical conference and exhibition, 27-29 October, Amsterdam, The Netherlands, 2014. doi: 10.2118/170641-MS.

Li LL, Yao J, Li Y, et al. Study of productivity calculation and distribution of staged multi-cluster fractured horizontal wells. Pet Explor Dev. 2014;41(4):504-8.

Pan BZ, Li D, Chen G, et al. Numerical simulation of wellbore and formation temperature fields in carbonate formations during drilling and shut-in in the presence of lost circulation. Pet Sci. 2014;11(2):293-9. doi:10.1007/s12182-014-0343-4.

Qu ZQ, Zhao YJ, Wen QZ, et al. Fracture parameter optimization in integral fracturing of horizontal wells. Pet Geol Recover Effic. 2012;19(4):106-11 (in Chinese).

Sam ZS, Zhou XY, Yang HJ, et al. Fractured reservoir modeling by discrete fracture network and seismic modeling in the Tarim Basin. China. Pet Sci. 2011;8(12):433-45.
Shang XT, He SL, Liu GF, et al. Breakdown pressure calculation of staged fracturing for horizontal wells. Drill Prod Technol. 2009;31(2):96-100 (in Chinese).

Sorek N, Moreno JA, Rice R, et al. Optimal hydraulic fracture angle in productivity maximized shale well design. In: Annual technical conference and exhibition, 27-29 October, Amsterdam, The Netherlands, 2014. doi:10.2118/170965-MS.

Wang T, Zhou WB, Chen JH, et al. Simulation of hydraulic fracturing using particle flow method and application in a coal mine. Int $\mathrm{J}$ Coal Geol. 2014a;121(5):1-13. doi:10.1016/j.coal.2013.10.012.

Wang H, Liao X, Zhao X, et al. Advances of technology study of stimulated reservoir volume in an unconventional reservoir. Spec Oil Gas Reserv. 2014b;21(2):8-15 (in Chinese).

Wei H, Li L, Wu X, et al. The analysis and theory research on the factor of multiple fractures during hydraulic fracturing of CBM wells. Proc Earth Planet Sci. 2011;22(3):231-7. doi:10.1016/j. proeps.2011.09.088.

Wu Q, Xu Y, Wang T, et al. The revolution of reservoir stimulation: an introduction to volume fracturing. Nat Gas Ind. 2011;31(4):7-11 (in Chinese).

$\mathrm{Wu} \mathrm{Q}, \mathrm{Xu} \mathrm{Y}$, Wang X, et al. Volume fracturing technology of unconventional reservoirs: connotation, design optimization and implementation. Pet Explor Dev. 2012;39(3):377-84.

$\mathrm{Xu}$ YB. Influential factors for fracture geometry as multi-fracture simultaneous extension. Pet Geol Oilfield Dev Daqing. 2009;28(3):89-92 (in Chinese).

Yao J, Sun H, Fan DY, et al. Numerical simulation of gas transport mechanisms in tight shale gas reservoirs. Pet Sci. 2013;10(5):528-37. doi:10.1007/s12182-013-0304-3.

Yin J, Guo JC, Zeng FH. Perforation spacing optimization for staged fracturing of horizontal well. Pet Drill Tech. 2012;40(5): 67-71 (in Chinese).

Zeng BQ, Cheng LS, Li CL, et al. Development evaluation of fractured horizontal wells in ultra-low permeability reservoirs. Acta Pet Sin. 2010;31(5):791-6 (in Chinese).

Zhang GQ, Chen M. Dynamic fracture propagation in hydraulic refracturing. J Pet Sci Eng. 2010a;70(3-4):266-72.

Zhang GQ, Chen M. Study of damage mechanism by production testing after acid fracturing of carbonate reservoir. Pet Sci Technol. 2010b;28(2):125-34.

Zhang GQ, Chen M. The relationship between the production rate and initiation location of new fractures in a refractured well. Pet Sci Technol. 2010c;28(7):655-66.

Zhang WM, Meng G, Wei X. A review on slip models for gas microflows. Microfluid Nanofluid. 2012;13(6):845-82.

Zhang YJ, Li ZW. Electricity generation from enhanced geothermal systems by oilfield produced water circulating through a reservoir stimulated by staged fracturing technology for horizontal wells: a case study in the Xujiaweizi area in Daqing Oilfield, China. Energy. 2014;78(6):788-805. doi:10.1016/j. energy.2014.10.073.

Zhao HF, Chen M, Jin Y, et al. Rock fracture kinetics of the fracture mesh system in shale gas reservoirs. Pet Explor Dev. 2012;39(4):465-70.

Zhou CN, Dong DZ, Wang SJ, et al. Geological characteristics, formation mechanism and resource potential of shale gas in China. Pet Explor Dev. 2010;37(6):641-53.

Zhu SY, Li HT, Yang MJ, et al. Optimization of fracture laying patterns of horizontal wells in multi-stage fracturing of a low permeability reservoir. Fault-Block Oil Gas Field. 2013;20(3):373-6 (in Chinese).

Ziarani AS, Aguilera R. Knudsen's permeability correction for tight porous media. Transp Porous Media. 2012;91(1):239-60. 